\title{
Pielonefrite Enfisematosa Fulminante Secundária a Neoplasia Urotelial com Fístula Renocólica
}

\section{Fulminant Emphysematous Pyelonephritis Secondary to Urothelial Neoplasia with Reno-Colic Fistula}

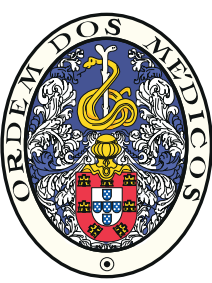

Ana Rita ELVAS $\square^{1}$, Bruno Jorge PEREIRA², Filipa CARREGA ${ }^{1}$, Leopoldina VICENTE1

Acta Med Port 2018 Feb;31(2):129-132 - https://doi.org/10.20344/amp.8869

\begin{abstract}
RESUMO
A pielonefrite enfisematosa é uma entidade pouco frequente e potencialmente fatal. O reconhecimento desta patologia permite a correta orientação precoce dos doentes. A diabetes e a obstrução ureteral são os principais fatores de risco identificados. Apresentase o caso de uma doente saudável, sem fatores de risco conhecidos, em que o motivo de ida ao serviço de urgência foi apenas uma dor lombar, acabando por evoluir com quadro de choque séptico nas primeiras horas. Os exames imagiológicos permitiram identificar a presença de gás perirrenal e subcutâneo o que orientou o correto diagnóstico (pielonefrite enfisematosa secundária a neoplasia urotelial fistulizada) e tratamento cirúrgico. Contudo, e como o estado clínico e analítico à admissão e no pós-operatório faziam prever a doente acabou por falecer. De referir ainda que este mesmo caso documenta uma bacteriemia por Sphingomonas paucimobilis (adquirida na comunidade) com lesões cavitadas a nível pulmonar (provável embolismo séptico).

Palavras-chave: Enfisema; Fístula Intestinal Fístula Urinária; Neoplasias da Bexiga Urinária; Pielonefrite
\end{abstract}

\section{ABSTRACT}

The emphysematous pyelonephritis is a uncommon and potentially fatal entity. The recognition of this condition enables the early correct management of patients. Diabetes and ureteral obstruction are the main risk factors identified. We present the case of a patient with no relevant risk factors or prior medical history, in which the reason of admission to the emergency department was back pain, eventually evolving into septic shock in the early hours. The imaging tests identified the presence of peri-renal and subcutaneous gas which guided the medical team to the right diagnosis (emphysematous pyelonephritis secondary to fistulized urothelial neoplasia) and the optimal surgical treatment. However, in the post-operative period the patient died, as the clinical condition and laboratory test results performed during the admission were predicting. It should also be mentioned that this same case illustrated a bacteraemia by Sphingomonas Paucimobilis (acquired in the community) with cavitated damage to lungs (probable septic embolism).

Keywords: Emphysema; Intestinal Fistula; Kidney Neoplasms; Pyelonephritis; Urinary Bladder Neoplasms; Urinary Fistula

\section{INTRODUÇÃO}

A pielonefrite enfisematosa é uma infeção pouco frequente, potencialmente fatal e necrotizante do parênquima renal e zonas circundantes. É mais frequente em diabéticos e mulheres; nos não-diabéticos usualmente a doença é menos agressiva e ocorre em associação com obstrução reno-uretérica. ${ }^{1,2} \mathrm{O}$ uso disseminado de métodos de imagem para o esclarecimento de patologia abdominal tem identificado um número crescente desta patologia, mostrando que poderá tratar-se de uma entidade subdiagnosticada. $^{2}$

O reconhecimento da formação de uma fístula renocólica é crucial para o correto diagnóstico e tratamento. A sua etiologia é variada, estando geralmente relacionada com lesões inflamatórias (que causam erosões ao nível dos órgãos adjacentes) ou traumáticas (relacionadas com procedimentos cirúrgicos). ${ }^{3-8}$

A apresentação deste caso justifica-se pela raridade e pela forma de apresentação fulminante de uma neoplasia do urotélio alto complicada com uma fístula renocólica e pielonefrite enfisematosa.

\section{CASO CLÍNICO}

Mulher 64 anos previamente saudável, com hábitos ta- bágicos e alcoólicos. Recorreu ao serviço de urgência (SU) com queixas de dor lombar tipo facada, crónica agudizada, sem história de traumatismo. Após exclusão de patologia ortopédica aguda foi orientada para a Medicina Interna. Negava outros sintomas, nomeadamente queixas génito-urinárias, respiratórias, gastrointestinais ou sintomas constitucionais. Objectivada palidez cutânea, sem outras alterações de relevo à observação. Controlo analítico com anemia normocítica e normocrómica (hemoglobina 9,5 g/ $\mathrm{dL}$ ), leucocitose $31000 / \mathrm{uL}$, neutrofilia $96,8 \%$, proteína C-reactiva $38,85 \mathrm{mg} / \mathrm{dL}$, ureia $91 \mathrm{mg} / \mathrm{dL}$, creatinina $1,8 \mathrm{mg} /$ $\mathrm{dL}$ e lactatos de $68 \mathrm{mg} / \mathrm{dL}$. Ainda no SU a dor evoluiu com irradiação para a região abdominal, com empastamento à palpação do flanco esquerdo e após alguns minutos aparecimento de sinais inflamatórios da parede abdominal que evoluíram para sinais de necrose em cerca de 45 minutos (Fig. 1). Iniciando também nessa altura quadro de instabilidade hemodinâmica com hipotensão e taquipneia.

A palpação abdominal evoluiu com crepitações sugestivas de enfisema subcutâneo. Manteve hipotensão grave, com necessidade de suporte aminérgico, e oligúria. Após discussão multidisciplinar iniciou empiricamente piperacilina/tazobactan e metronidazol. Realizou tomografia

1. Serviço de Medicina. Centro Hospitalar Cova da Beira. Covilhã. Portugal.

2. Serviço de Urologia. Centro Hospitalar Cova da Beira. Covilhã. Portugal.

$\triangle$ Autor correspondente: Ana Rita Elvas. arita.ge@gmail.com

Recebido: 20 de fevereiro de 2017 - Aceite: 18 de agosto de 2017 | Copyright @ Ordem dos Médicos 2018 


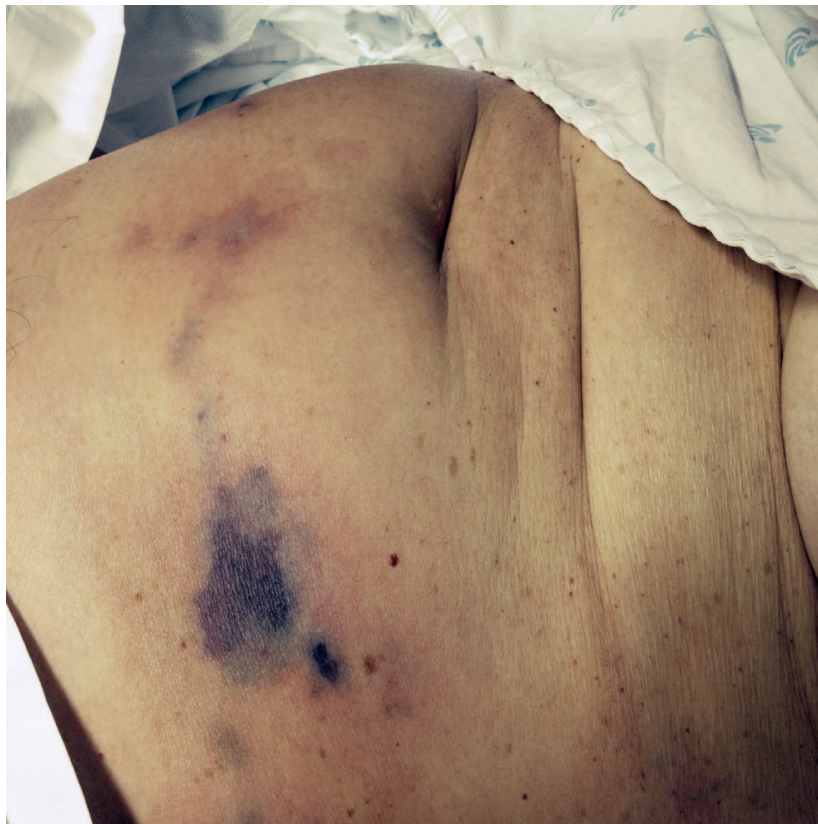

Figura 1 - Sinais de isquémia da parede abdominal identificados no SU

computorizada (TC) abdominal que revelou lesão com $8 \mathrm{~cm}$ no rim esquerdo com presença de gás no sistema coletor, no parênquima e ao redor do rim (Fig. 2). Foi colocada a hipótese de pielonefrite enfisematosa e encaminhada para cirurgia. A TC tórax mostrou lesões torácicas cavitadas (Fig. 3).

No bloco operatório objetivada extensa área de fasceíte necrotizante abdominal, irressecável na totalidade, associada a liquefacção do retroperitoneu. Realizada nefrectomia total esquerda, tendo-se identificado fístula renocólica pelo

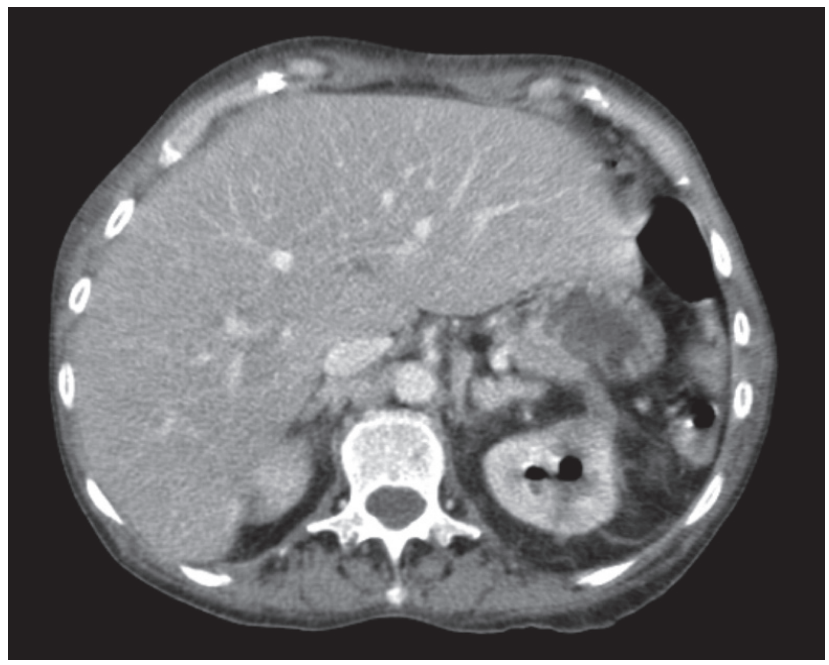

Figura 2 - TC abdominal revelando gás no rim esquerdo e parede abdominal anterior

que se procedeu à remoção do colón adjacente (Fig. 4).

Após cirurgia manteve necessidade de suporte aminérgico, hemodiafiltração e ventilação mecânica invasiva, com agravamento analítico progressivo dos parâmetros de infecção, lesão renal e hepática. Agravamento da infeção necrotizante dos tecidos, com formação de vesículas de conteúdo seroso gelatinoso e áreas de necrose com cheiro fétido intenso (Fig. 5). O óbito foi declarado cerca de 48 horas após a admissão

O pús da loca renal esquerda revelou Escherichia coli e Enterococcus faecalis. A identificação destes microorganismos, nomeadamente da Escherichia coli está de acordo com a literatura que o classificam como o mais

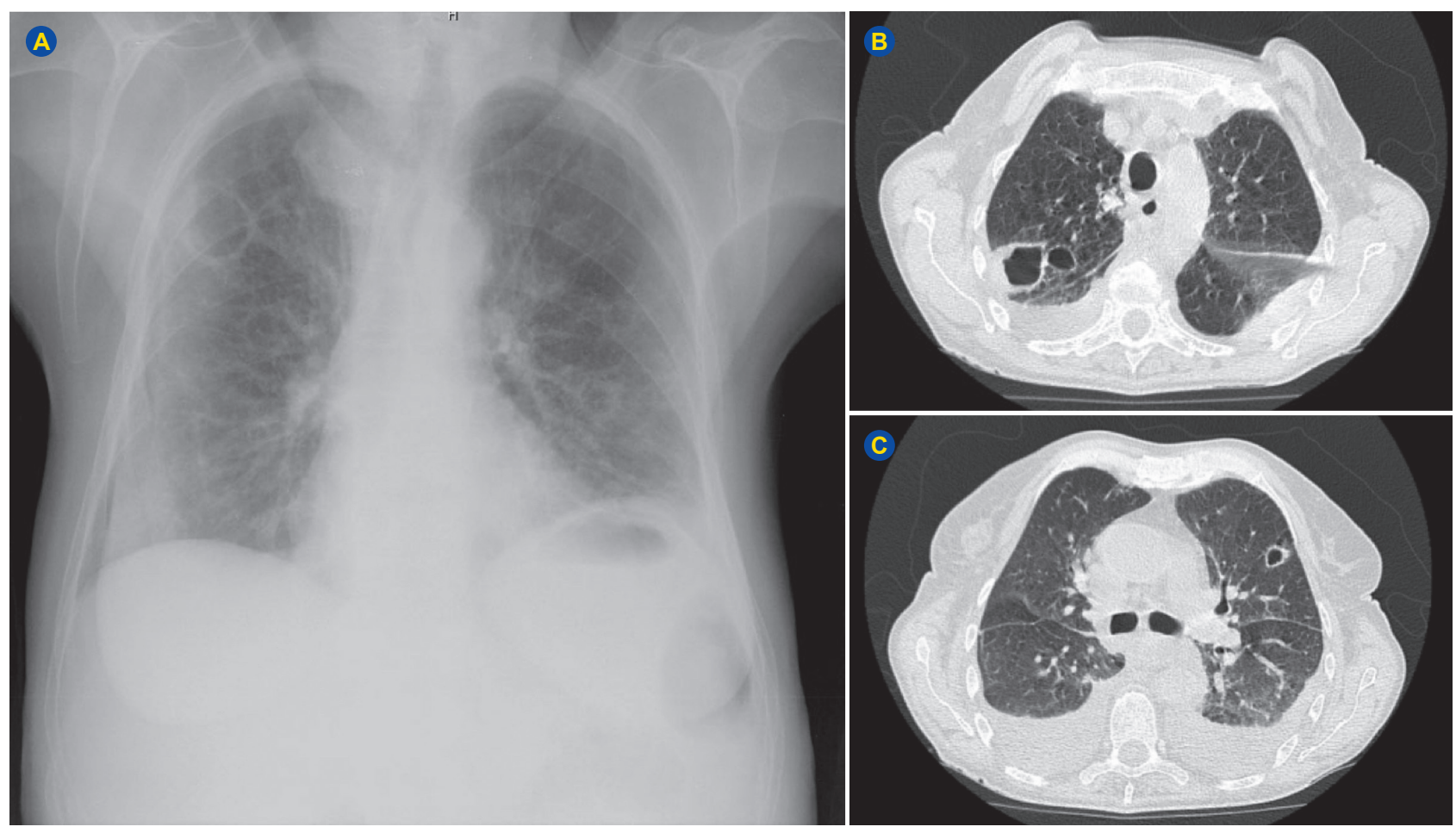

Figura 3 - Radiografia de tórax mostrando lesões cavitadas (A). TC tórax confirmando as mesmas lesões cavitadas dispersas por ambos os campos pulmonares e derrame pleural bilateral (B e C). 

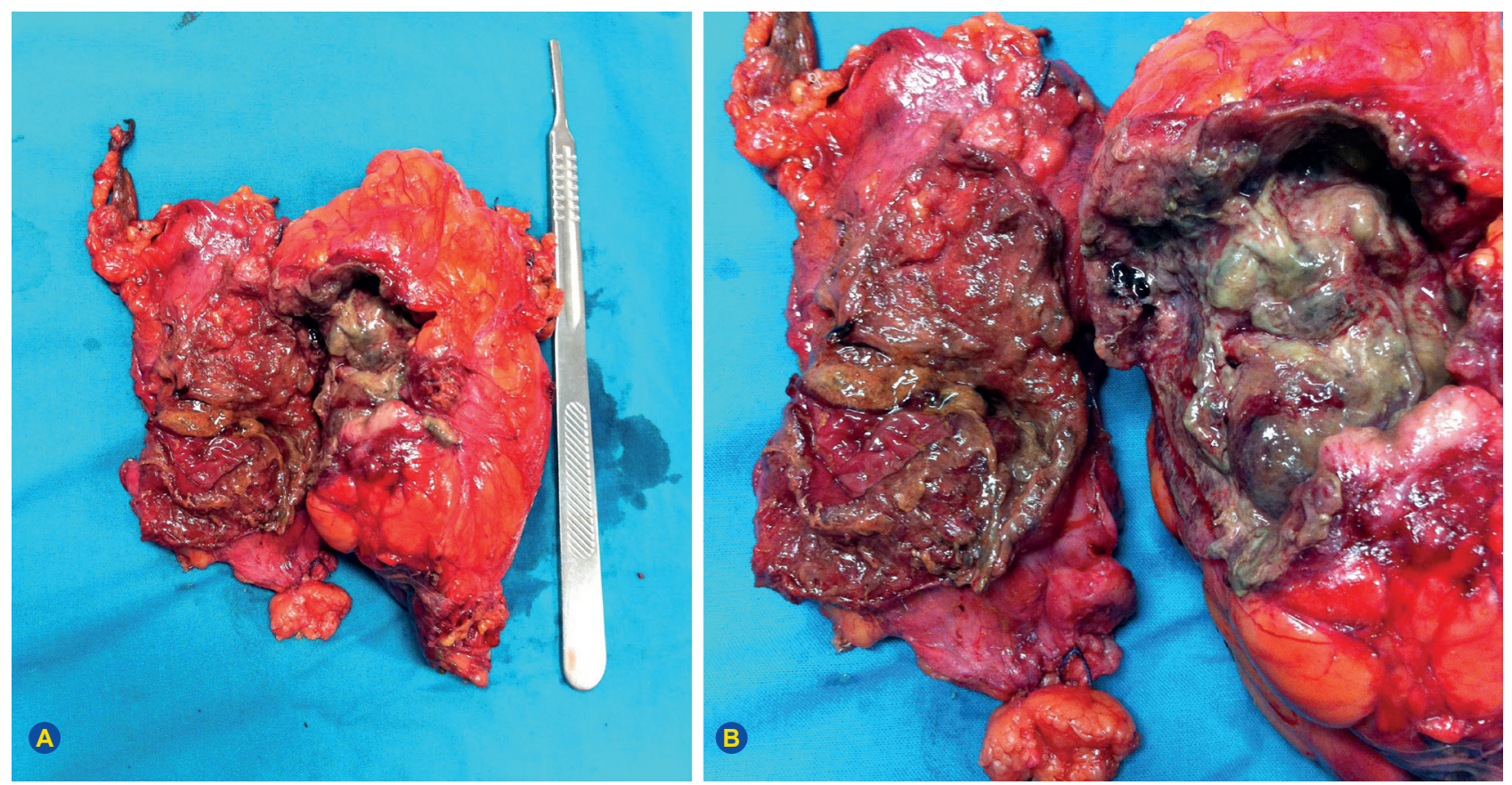

Figura 4 - Segmento de cólon esquerdo (ângulo esplénico) envolvido pela neoplasia e pela fístula renocólica e peça de nefrectomia total com exposição do bacinete fistulizado e recoberto por conteúdo purulento/fecal

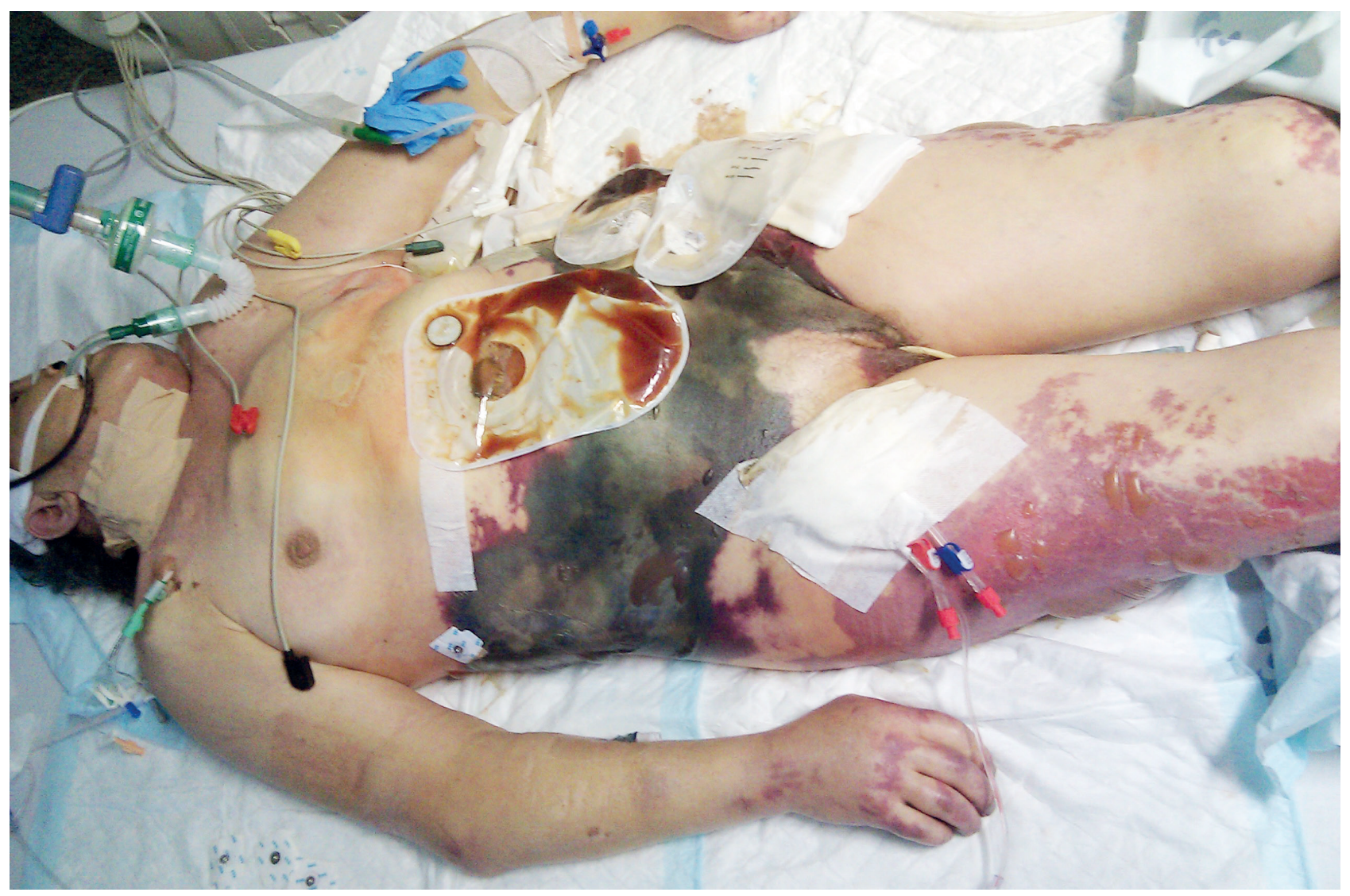

Figura 5 - Evolução pós-operatório às 24 horas

frequente causador da pielonefrite enfisematosa. As quatro hemoculturas colhidas na admissão foram positivas para Sphingomonas (Pseudomonas) paucimobilis. Este microorganismo é uma causa rara de infecção no ser humano e está por norma associado a imunossupressão, maioritaria- mente a neoplasias. De acordo com o descrito por Kuo, a bacteriemia por S. paucimobilis pode estar associada a embolismos sépticos a nível pulmonar, que justificam e enquadram as lesões torácicas encontradas nesta doente (Fig. 3). ${ }^{9,10}$ Contudo, uma vez que a doente não foi autopsiada 
não se podem excluir outros diagnósticos, nomeadamente metástases infetadas.

O exame histológico do rim esquerdo revelou neoplasia urotelial com áreas de extensa necrose, áreas de carcinoma epidermóide queratinizante e áreas pouco diferenciadas que infiltravam extensamente o parênquima renal e o cólon adjacente (neoplasia urotelial pT4). Este resultado histológico acabou por confirmar o mau prognóstico da doente, bem como justificar o estado de imunossupressão que condicionou uma evolução rapidamente progressiva e fatal.

\section{DISCUSSÃO}

As fístulas renocólicas espontâneas resultam frequentemente de processos inflamatórios ou são secundárias a neoplasias. ${ }^{3,5,8}$ A tuberculose genitourinária e pionefrose com cálculos são as causas renais mais frequentes. As causas gastrointestinais são menos frequentes e devem-se principalmente a neoplasias e divertículos. A sua incidência tem diminuído graças ao reconhecimento atempado e tratamento efetivo das infeções renais. ${ }^{3,5,8} \mathrm{~A}$ sua formação é baseada no desenvolvimento de um abcesso renal com drenagem para o cólon, que geralmente está também atingido pela inflamação. ${ }^{3} \mathrm{~A}$ apresentação clínica depende do local e do tamanho da fístula. Podem manifestar-se por infeções urinárias de repetição, perda ponderal, astenia; diarreia; pneumatúria ou fecalúria; raramente, podem manifestar-se por obstrução intestinal. ${ }^{3,5} \mathrm{O}$ tratamento nestes casos é predominantemente cirúrgico. ${ }^{3}$

A característica principal da pielonefrite enfisematosa é a presença de gás no parênquima renal, produzido por microorganismos, nomeadamente E. coli, Klebsiella e Proteus, geralmente associado a níveis elevados de glicose, defeitos na perfusão tecidular e na resposta imunitária. ${ }^{1,2}$ As manifestações clínicas mais comuns são sobreponíveis às de uma pielonefrite aguda comum, com febre, dor no flanco e piúria; menos frequentes são queixas inespecíficas como dor abdominal, vómitos, prostração, choque, crepitações no flanco, pneumatúria ou lesão renal aguda.

\section{REFERÊNCIAS}

1. Sharma PK, Sharma R, Vijay MK, Tiwari P, Goel A, Kundu AK. Emphysematous pyelonephritis: our experience with conservative management in 14 cases. Urol Ann. 2013;6:157-62.

2. Huang JJ, Tseng CC. Emphysematous Pyelonephritis. Arch Intern Med. 2000;160:797-805.

3. Manzanilla-Garcíaa HA, Sánchez-Alvaradob JP, Rosas-Navab JE, Soto-Abrahamc V. Fístula renocólica secundaria a adenocarcinoma de colon. Rev Mex Urol. 2010;70:174-8.

4. Parasher R, Sasidharan. Spontaneous reno-colic fistula. Indian J Urol. 2000;17:64-5.

5. Hardikar JV. Reno alimentary fistulae. J Dental Med Sci. 2014;3:77-9.

6. Shah I, Gupta R, Gupta CL, Robani I. Renocolic fistula secondary to renal calculus with tuberculosis. JK-Practitioner. 2003;10:296-7.
Os principais fatores de risco para pielonefrite enfisematosa são diabetes e obstrução do trato urinário. ${ }^{1,2}$ Os níveis de creatinina sérica superior a $1,4 \mathrm{mg} / \mathrm{dL}$ e plaquetas inferiores a $60000 / \mathrm{mm}^{3}$, assim como sinais de choque, são fatores de mau prognóstico, com uma taxa de mortalidade que aumenta de $69 \%$ para $92 \%$ nos casos mais graves. ${ }^{11}$ A doente referida neste caso apresentava todos os critérios de gravidade e mau prognóstico, que justificaram a abordagem cirúrgica imediata, com implementação de medidas intensivas de estabilização hemodinâmica.

Serve este caso para alertar para a existência desta entidade clínica pouco usual e que pode justificar casos de sepsis sem ponto de partida evidente e que implicam uma atuação médico-cirúrgica atempada e concertada. Reforça ainda a importância da valorização de todos os sintomas e sinais manifestados.

Fica ainda documentado um caso de bacteriémia adquirida na comunidade por Sphingomonas paucimobilis com embolização pulmonar numa doente imunodeprimida por neoplasia.

\section{PROTECÇÃO DE PESSOAS E ANIMAIS}

Os autores declaram que os procedimentos seguidos estavam de acordo com os regulamentos estabelecidos pelos responsáveis da Comissão de Investigação Clínica e Ética e de acordo com a Declaração de Helsínquia da Associação Médica Mundial.

\section{CONFIDENCIALIDADE DOS DADOS}

Consentimento do doente obtido.

\section{CONFLITOS DE INTERESSE}

Os autores declaram não terem qualquer conflito de interesse relativamente ao presente artigo.

\section{FONTES DE FINANCIAMENTO}

Os autores declaram não ter recebido subsídios ou bolsas para a elaboração do artigo.

7. Bissada NK, Cole AT, Fried FA. Reno alimentary fistula: an unusual urological problem. J Urol. 1973;110:273-6.

8. Singh G, Gordon-Harris L. Case report: tubercular reno-colic fistula. Indian J Radiol Imaging. 2004;15:295-7.

9. Kuo IC, Lu PL, Lin WR, Lin CY, Chang YW, Chen TC, et al. Sphingomonas paucimobilis bacteraemia and septic arthritis in a diabetic patient presenting with septic pulmonary emboli. J Med Microbiol. 2009;58:1259-63.

10. Lin JN, Lai $\mathrm{CH}$, Chen $\mathrm{YH}$, Lin $\mathrm{HL}$, Huang $\mathrm{CK}$, Chen WFet al. Sphingomonas paucimobilis bacteriemia in humana: 16 case reports and literature review. J Microbiol Immunol Infect. 2010;43:35-42.

11. Wan YL, Lo SK, Bullard MJ, Chang PL, Lee TY. Predictors of outcome in emphysematous pyelonephritis. J Urol. 1998;159:369-73.3. 